\title{
Desempenho Agronômico do Sorgo em Função de Doses e ÉPOCAS DE APLICAÇÃo do HERBICIDA 2,4-D ${ }^{1}$
}

\author{
Agronomic Performance of Sorghum as a Response to 2,4-D Application Dosage and Times
}

\author{
PETTER, F.A. ${ }^{2}$, PACHECO, L.P. ${ }^{2}$, ALCÂNTARA NETO, F. ${ }^{2}$, ZUFFO, A.M. ${ }^{3}$, PROCÓPIO, S.O. ${ }^{4}$ e \\ ALMEIDA, F.A. ${ }^{2}$
}

\begin{abstract}
RESUMO - A cultura do sorgo está inserida no plano atual de manejo dos sistemas agrícolas nos cerrados, todavia são escassos os estudos em campo quanto à seletividade e comportamento da cultura ao herbicida 2,4-D. Objetivou-se neste trabalho avaliar os efeitos do 2,4-D sobre o crescimento das plantas, a produção de fitomassa seca e fitomassa verde e a produtividade de grãos na cultura do sorgo. O experimento foi realizado entre janeiro e maio de 2008, em Nova Xavantina-MT, em Latossolo Vermelho-Amarelo distrófico. O sorgo (cultivar Buster) foi semeado em área cultivada sob sistema de plantio direto, em espaçamento de 0,50 m entre linhas, distribuindo-se 10 sementes por metro. Os tratamentos foram dispostos em esquema fatorial 4 x 4, envolvendo quatro doses de 2,4-D (0, 335, 670 e $\left.1.005 \mathrm{gha}^{-1}\right)$ e quatro épocas de aplicação (pré-semeadura, três folhas expandidas, seis folhas expandidas e pré-florescimento). Utilizou-se o delineamento de blocos casualizados com quatro repetições. O controle de plantas daninhas na cultura foi realizado manualmente, com utilização de enxada. Verificou-se efeito fitotóxico à cultura do sorgo pelo 2,4-D aos 15 dias após a aplicação (DAA), independentemente da dose ou época de aplicação. O incremento das doses de 2,4-D provocou redução linear da altura de plantas, acúmulo de fitomassa verde e acúmulo de fitomassa seca, tanto aos 30 DAA quanto no ponto de rolagem. A aplicação do 2,4-D prejudica a produtividade do sorgo, especialmente em doses acima de $1.005 \mathrm{~g} \mathrm{ha}^{-1}$ e.a. e em aplicações tardias. De maneira geral, a utilização do 2,4-D em pré-semeadura mostrou-se uma boa alternativa no manejo das plantas daninhas na cultura do sorgo.
\end{abstract}

Palavras-chave: auxina sintética, Sorghum bicolor, seletividade, produtividade, crescimento.

\begin{abstract}
Sorghum is part of the current plan of agricultural system management for the cerrado. However, few field studies have been carried out on this culture's behavior and selectivity towards herbicide 2, 4 D. The objective of this study was to evaluate the effects of 2, 4-D on plant growth, dry matter production and green biomass and grain yield in sorghum. The experiment was conducted between January and May 2008 in Nova Xavantina-MT in dystrophic Oxisol. Sorghum (cv. Buster) was sown in a cultivated area under no-tillage, with $0.50 \mathrm{~m}$ spacing between rows, and ten seeds distributed per meter. Treatments were arranged in a $4 \times 4$, involving four levels of 2, 4- $D(0,335$, 670 , and $1.005 \mathrm{~g} \mathrm{ha}^{-1}$ ) and four application times (pre-sowing, three fully-expanded leaves, six leaves, and pre-flowering).A randomized block design was used, with four replications. Weed control in the culture was performed manually, using a hoe. Toxic effects caused to sorghum by 2, 4-D were observed at 15 days after application (DAA), regardless of dose or time of application. The increasing levels of 2, 4-D caused a linear reduction in plant height, biomass and green dry matter accumulation, both at 30 DAA as the point of rollover. The application of 2, 4-D affected sorghum yield, especially at doses above $1.005 \mathrm{~g} \mathrm{ha}^{-1}$ and late applications. In general, the use of 2, 4-D in pre-sowing proved to be a good alternative for the management of weeds in sorghum crop.
\end{abstract}

Keywords: synthetic auxins, Sorghum bicolor, selectivity, productivity, growth.

Recebido para publicação em 26.2.2011 e aprovado em 17.6.2011.

2 Professor Adjunto do Programa de Pós-Graduação em Agronomia-Fitotecnia, Universidade Federal do Piauí - UFPI/Campus Prof ${ }^{a}$. Cinobelina Elvas - UFPI/CPCE, 64900-000 Bom Jesus-PI, <petter@ufpi.edu.br>; <leandroppacheco@gmail.com>; $<$ fneto@ufpi.edu.br>; <fernandes@ufpi.edu.br>; ${ }^{3}$ Mestrando do Programa de Pós-Graduação em Agronomia-Fitotecnia, UFPI, <alan_zuffo@hotmal.com>; ${ }^{4}$ Pesquisador, Embrapa Soja, Caixa Postal 231,86001-970 Londrina-PR, <procopio.so@gmail.com>. 


\section{INTRODUÇÃO}

O sorgo granífero (Sorghum bicolor) tem atraído um grande número de agricultores empresariais que buscam boa rentabilidade no sistema produtivo (Almeida Filho et al., 2010). Na região do cerrado, o cultivo do sorgo assume destaque em substituição ao milho, principalmente em plantios de sucessão às culturas de verão, trazendo grandes vantagens econômicas ao produtor na formação de palhada, grãos e forragem (Fonseca et al., 2008). Nessas regiões, na época em que ocorre o desenvolvimento da segunda safra, o volume e a frequência de chuvas costumam ser oscilantes e insuficientes. Segundo Magalhães et al. (2000), o sorgo é eficiente na conversão de água em matéria seca, sendo dotado de importantes mecanismos bioquímicos e morfológicos que lhe conferem tolerância à seca, superando culturas como o milho e o trigo.

Um dos principais problemas na cultura do sorgo tem sido o controle de plantas daninhas, as quais prejudicam a cultura devido à competição por luz, água, e nutrientes. Tamado et al. (2002) observaram que, não havendo o controle das plantas daninhas nas quatro primeiras semanas após a emergência do sorgo, pode ocorrer redução na produtividade de grãos da ordem de 35 a $90 \%$.

Pertencente ao grupo químico dos ácidos fenoxiacéticos, também conhecido como auxinas sintéticas, o herbicida 2,4-D (ácido ariloxialcanoico) é caracterizado por ocasionar em plantas sensiveis diversos distúrbios metabólicos, como crescimento anormal, morte dos tecidos radiculares, epinastia e obstrução do floema (Rodrigues \& Almeida, 2005). Apresenta elevado potencial de controle em dicotiledôneas, sendo recomendado para aplicação em pós-emergência na cultura do sorgo (Shaw \& Arnold, 2002). Todavia, como já foi verificado em alguns trabalhos (Penckowski et al., 2003; Farinelli et al., 2005; Pacheco et al., 2007) a respeito da sua seletividade a algumas gramineas, os resultados são divergentes quanto ao efeito da aplicação desse herbicida. De acordo com Abit et al. (2009), até então, no sorgo, poucos estudos foram realizados.

Dan et al. (2010) avaliaram a seletividade do herbicida 2,4-D, aplicado em pós-emergência, em três estádios de desenvolvimento do sorgo granífero, sob condições controladas. Entretanto, são escassos os estudos em campo quanto à seletividade e ao comportamento do sorgo quando submetido à aplicação do herbicida 2,4-D em pré-semeadura e pós-emergência da cultura.

Objetivou-se com este trabalho avaliar os efeitos da aplicação em pré e pós-emergência da cultura de diferentes doses do herbicida 2,4-D sobre o desenvolvimento e a produtividade da cultura do sorgo na região dos cerrados.

\section{MATERIAL E MÉTODOS}

O experimento foi conduzido em campo no município de Nova Xavantina-MT, em área anteriormente cultivada com soja no sistema de plantio direto, localizada a $14^{\circ} 39^{\prime} 38^{\prime \prime}$ de latitude, $52^{\circ} 18^{\prime} 42^{\prime \prime}$ de longitude e altitude de $320 \mathrm{~m}$. O estudo foi conduzido no período de janeiro a junho de 2008, em solo classificado como Latossolo Amarelo distrófico - LAd (Embrapa, 1999).

Na análise química e física do solo de amostras coletadas na profundidade de $0-20 \mathrm{~cm}$, antes da implantação do experimento, verificou-se: $\mathrm{pH}\left(\mathrm{H}_{2} \mathrm{O}\right)$ : 5,7; fósforo ( $\mathrm{P}$, método de Mehlich): 7,7 mg dm${ }^{-3}$; potássio $\left(\mathrm{K}^{+}\right): 72 \mathrm{mg} \mathrm{dm}^{-3}$; cálcio $\left(\mathrm{Ca}^{2+}\right): 2,4 \mathrm{cmol}_{\mathrm{c}} \mathrm{dm}^{-3}$; magnésio $\left(\mathrm{Mg}^{2+}\right)$ : $0,8 \mathrm{cmol}_{\mathrm{c}} \mathrm{dm}^{-3}$; alumínio $\left(\mathrm{Al}^{3+}\right): 0,1 \mathrm{cmol}_{\mathrm{c}} \mathrm{dm}^{-3}$; acidez potencial $\left(\mathrm{H}^{+}+\mathrm{Al}^{3+}\right): 3,98 \mathrm{cmol}_{\mathrm{c}} \mathrm{dm}^{-3}$; saturação por bases (V\%): 46; capacidade de troca catiônica (CTC): $7,3 \mathrm{cmol}_{\mathrm{c}} \mathrm{dm}^{-3}$; matéria orgânica (MO): $12,6 \mathrm{~g} \mathrm{~kg}^{-1}$; ferro $(\mathrm{Fe})$ : $70,0 \mathrm{mg} \mathrm{dm}^{-3}$; manganês (Mn): 43,0 $\mathrm{mg} \mathrm{dm}^{-3}$; zinco $(\mathrm{Zn})$ : 25,0 $\mathrm{mg} \mathrm{dm}^{-3}$; cobre $(\mathrm{Cu}): 1,7 \mathrm{mg} \mathrm{dm}^{-3}$; argila: $307 \mathrm{~g} \mathrm{~kg}^{-1}$; silte: $73 \mathrm{~g} \mathrm{~kg}^{-1}$; e areia: $620 \mathrm{~g} \mathrm{~kg}^{-1}$.

Dois dias antes da semeadura, realizou-se a dessecação química da vegetação na área experimental, utilizando-se $1.080 \mathrm{~g} \mathrm{ha}^{-1} \mathrm{de}$ equivalente ácido (e.a.) de glyphosate. A semeadura do sorgo (cv. Buster) foi feita em janeiro de 2008, com auxilio de semeadora-adubadora tratorizada ajustada para o espaçamento de 0,50 m entre linhas, distribuindo-se 10 sementes por metro. A adubação no sulco de semeadura constituiu-se de $300 \mathrm{~kg} \mathrm{ha}^{-1}$ da fórmula 05-25-15. Aos 25 dias após a emergência, aplicaram-se $50 \mathrm{~kg} \mathrm{ha}^{-1}$ de nitrogênio, utilizando ureia como fonte. 
Os tratamentos foram dispostos em esquema fatorial envolvendo quatro doses do herbicida 2,4-D amina (0, 335, 670 e $1.005 \mathrm{~g} \mathrm{ha}^{-1}$ e.a.) e quatro diferentes épocas de aplicação (présemeadura, três folhas expandidas, seis folhas expandidas e pré-florescimento). Utilizou-se o delineamento de blocos ao acaso, com quatro repetições. As parcelas constituíram-se de nove linhas da cultura com $5 \mathrm{~m}$ de comprimento, totalizando $22,5 \mathrm{~m}^{2}$, com área útil de $10,5 \mathrm{~m}^{2}$, referente à porção central das parcelas.

As diferentes doses do herbicida 2,4-D foram aplicadas utilizando-se pulverizador costal pressurizado com $\mathrm{CO}_{2}$, acoplado à barra com quatro pontas de pulverização XR 110/02 a pressão constante de $2 \mathrm{kgf} \mathrm{cm}^{-2}$, aplicando-se volume de calda equivalente a $125 \mathrm{~L} \mathrm{ha}^{-1}$. As condições ambientais no momento da aplicação dos tratamentos foram: temperatura média de $28{ }^{\circ} \mathrm{C}$, umidade relativa média de $78 \%$ e velocidade do vento variando de 3 a $8 \mathrm{~km} \mathrm{~h}^{-1}$. Todas as parcelas foram mantidas livres da convivência com plantas daninhas por meio de capinas manuais, independentemente do tratamento aplicado.

As características avaliadas no sorgo foram a ocorrência de sintomas de intoxicação das plantas ao 2,4-D, aos 15 dias após a aplicação (DAA); a altura de plantas aos 15 e aos 30 DAA, visando posteriormente verificar a redução na altura das plantas; a fitomassa verde e fitomassa seca no ponto de rolagem, ou seja, no período em que as plantas apresentam o máximo de acúmulo de fitomassa seca (início do enchimento de grãos); e a produtividade. Para avaliação da ocorrência de sintomas de intoxicação, realizou-se uma avaliação visual, utilizando-se uma escala percentual de notas, em que zero (0) representou a ausência de sintomas e cem $(100,0)$ a morte de todas as plantas da parcela. A altura de plantas foi avaliada medindo-se do colo até a extremidade final do meristema apical. A fitomassa verde e a fitomassa seca da parte aérea das plantas de sorgo foram estimadas coletando-se 10 plantas por parcela. O material coletado foi seco em estufa de ventilação forçada a $70{ }^{\circ} \mathrm{C}$ por 72 horas, para determinação da fitomassa seca. A produtividade foi estimada colhendose quatro amostras de $2 \mathrm{~m}$ na porção central da parcela. O material colhido foi pesado e teve a umidade corrigida para $13 \%$; os resultados foram transformados para $\mathrm{kg} \mathrm{ha}^{-1}$.

Os dados foram submetidos à análise de variância, sendo o efeito das diferentes épocas de aplicação do herbicida estudado pelo teste de Scott-Knott $(p<0,05)$, e o efeito das doses de 2,4-D, estudado por meio de análise de regressão, associando os coeficientes de correlação $(p<0,05)$ e determinação a cada modelo de regressão. Quanto à análise de fitointoxicação, os dados foram transformados em arc-seno $(x+1)^{0,5}$, visando seguir os pressupostos necessários da análise de variância; contudo, os valores apresentados são as médias originais.

\section{RESULTADOS E DISCUSSÃO}

Independentemente da época de aplicação, todas as doses estudadas de 2,4-D causaram efeito fitotóxico à cultura do sorgo (Figura 1), sendo o efeito progressivo à medida que se aumentaram as doses do herbicida. Observouse menor efeito deletério do 2,4-D sobre o sorgo quando aplicado em pré-florescimento, demonstrando que nessa fase há maior tolerância das plantas ao uso desse herbicida. Esse fato pode ser atribuído à maior capacidade de metabolização do herbicida pela cultura, associado ainda à diferenciação morfológica das plantas nesse estádio, como maior espessura da cutícula (Vidal, 2002) e elevado índice de área foliar (IAF), uma vez que, com maiores IAFs, maiores serão as doses necessárias do herbicida para causar os mesmos efeitos (Stone \& Pereira, 1994).

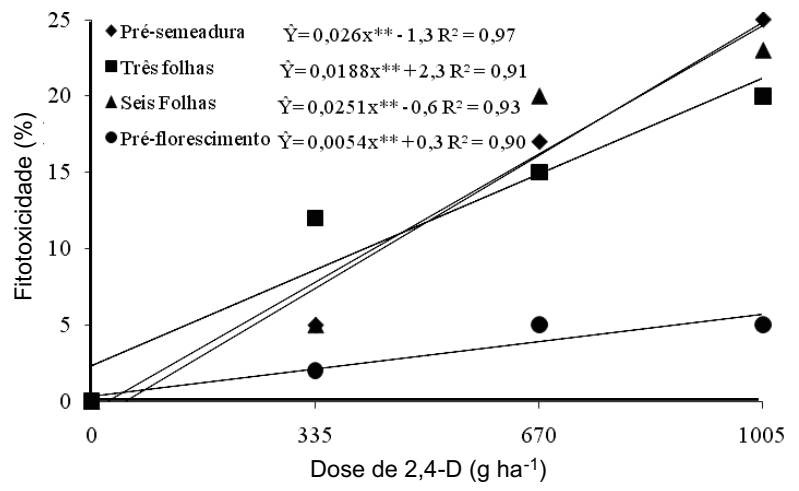

Figura 1 - Intoxicação em plantas de sorgo aos 15 dias, em função de épocas de aplicação e doses do herbicida 2,4-D. Nova Xavantina-MT, 2008. 
Observou-se também intoxicação das plantas de sorgo quando o 2,4-D foi aplicado em pré-semeadura, porém esses efeitos desapareceram 15 dias após a avaliação. Silva et al. (2007) também afirmaram que a atividade residual do 2,4-D em condições pluviométricas boas, associada a solos arenosos, não excede 30 dias.

Não se observou interação entre os fatores época de aplicação e doses do herbicida quanto à capacidade de redução na altura das plantas, porém houve efeito isolado da variável dose de herbicida (Tabela 1). Embora a época de aplicação não tenha influenciado significativamente a altura de plantas, as maiores doses de 2,4-D aplicadas nos estádios iniciais de desenvolvimento da cultura proporcionaram menor crescimento das plantas. Esse resultado certamente está relacionado com os padrões de translocação de fotoassimilados em direção aos meristemas, que é o principal local de atuação dos herbicidas auxínicos, nas plantas em estádios iniciais de desenvolvimento. Além disso, plantas em estádios de desenvolvimento avançados podem apresentar maiores quantidades de ceras epicuticulares, constituindo uma barreira físico-química à penetração dos herbicidas pelas folhas. De acordo com Silva et al. (2007), apesar de a constituição física e química da cutícula ser a mesma nos diferentes estádios de desenvolvimento, cutículas de folhas mais novas são mais permeáveis.

O aumento das doses de 2,4-D proporcionou linearmente maiores incrementos na redução da altura das plantas de sorgo (Figura 2) aos 15 e 30 dias após a aplicação (DAA). A aplicação de $1.005 \mathrm{~g} \mathrm{ha}^{-1}$ do herbicida provocou reduções de 13 e $14 \%$, respectivamente aos 15 e aos 30 DAA. Dan et al. (2010) não verificaram redução na altura de plantas com a aplicação de 2,4-D em sorgo granifero; contudo, Pacheco et al. (2007) observaram redução de $21 \%$ na altura de plantas de milheto com a aplicação

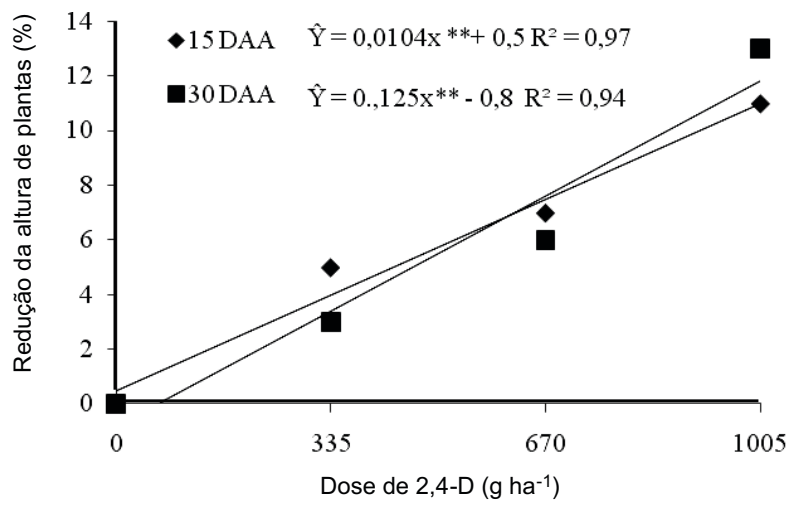

Figura 2 - Valores médios da porcentagem de redução na altura de plantas de sorgo aos 15 e 30 dias após a aplicação do herbicida 2,4-D. Nova Xavantina-MT, 2008

Tabela 1 - Porcentagem de redução da altura de plantas de sorgo após 15 e 30 dias da aplicação do herbicida 2,4-D, em cinco diferentes épocas. Nova Xavantina-MT, 2008

\begin{tabular}{|c|c|c|c|c|c|}
\hline \multirow{3}{*}{ Estádio da planta no momento da aplicação } & \multicolumn{5}{|c|}{ Dose do herbicida 2,4-D (g ha ${ }^{-1}$ e.a. $)$} \\
\hline & 0 & 335 & 670 & 1.005 & Média \\
\hline & \multicolumn{5}{|c|}{$\%$ de redução na altura de plantas aos $15 \mathrm{DAA}$} \\
\hline Pré-semeadura & 0 & 5 & 6 & 11 & $5^{\mathrm{ns}}$ \\
\hline Três folhas expandidas & 0 & 8 & 11 & 15 & 8 \\
\hline Seis folhas expandidas & 0 & 11 & 12 & 17 & 10 \\
\hline Pré-florescimento & 0 & 2 & 4 & 8 & 3 \\
\hline \multirow[t]{2}{*}{ Média } & 0 & 6 & 8 & 13 & 7 \\
\hline & \multicolumn{5}{|c|}{ \% de redução na altura de plantas aos $30 \mathrm{DAA}$} \\
\hline Pré-semeadura & 0 & 4 & 6 & 15 & $6^{\mathrm{ns}}$ \\
\hline Três folhas expandidas & 0 & 1 & 3 & 21 & 6 \\
\hline Seis folhas expandidas & 0 & 5 & 8 & 9 & 5 \\
\hline Pré-florescimento & 0 & 2 & 8 & 8 & 5 \\
\hline Média & 0 & 3 & 6 & 14 & 6 \\
\hline
\end{tabular}

${ }^{\mathrm{ns}}$ não significativo a $5 \%$ de probabilidade pelo teste $\mathrm{F}$. 
de $1.005 \mathrm{~g} \mathrm{ha}^{-1}$ de 2,4-D. Esses resultados contrastantes se devem a variações no comportamento de cultivares de sorgo quanto à sensibilidade ao herbicida 2,4-D, o que está associado a variações genéticas dos diferentes materiais (Geraldo et al., 2000).

Quanto à redução de fitomassa verde e fitomassa seca da parte aérea do sorgo aos 30 DAA, novamente não se verificou interação dos fatores época de aplicação e doses do herbicida 2,4-D. A época de aplicação do 2,4-D que proporcionou as menores reduções no acúmulo de fitomassa verde e fitomassa seca das plantas de sorgo foi em pré-semeadura (Tabela 2). D'Antonino et al. (2009) não verificaram efeito significativo do 2,4-D aos 45 dias após a emergência (DAE), mas notaram redução de $7 \%$ da fitomassa seca da parte aérea de plantas de sorgo - valor este muito próximo ao encontrado neste trabalho, que foi de $8 \%$. A baixa persistência do herbicida 2,4-D na forma amina deve-se às suas características físico-químicas, apresentando baixo coeficiente de adsorção (Koc) e alta solubilidade (Rodrigues \& Almeida, 2005), tornando-o suscetível à lixiviação, sobretudo em solos de textura média e com boas condições de precipitação.

O incremento das doses de 2,4-D provocou reduções lineares de até cerca de 24 e $26 \%$ no acúmulo de fitomassa verde e fitomassa seca, respectivamente, aos 30 DAA (Figura 3). Dan et al. (2010), em casa de vegetação, verificaram redução linear da massa seca da parte aérea com o aumento de doses de 2,4-D, que chegou a $27 \%$ com a dose de $1.608 \mathrm{~g} \mathrm{ha}^{-1}$. Esse menor acúmulo de fitomassa é um reflexo do efeito fitotóxico do herbicida (Figura 1) e da redução da altura das plantas (Figura 2), uma vez que plantas intoxicadas com o herbicida 2,4-D apresentam menor atividade metabólica.

A fitomassa seca da parte aérea no ponto de rolagem apresentou o menor acúmulo

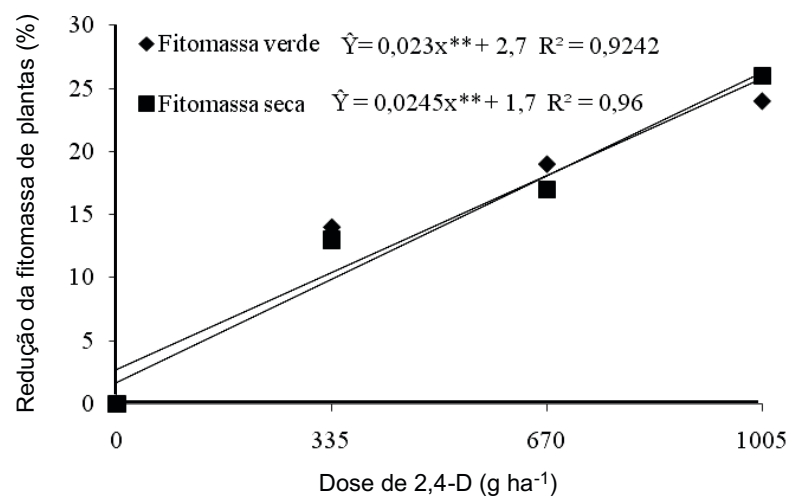

Figura 3 - Valores médios da porcentagem de redução da fitomassa verde e seca das plantas de sorgo aos 30 dias após a aplicação do herbicida 2,4-D. Nova XavantinaMT, 2008

Tabela 2 - Porcentagem de redução da fitomassa verde e seca de plantas de sorgo após 30 dias da aplicação do herbicida 2,4-D, em quatro diferentes épocas. Nova Xavantina-MT, 2008

\begin{tabular}{|c|c|c|c|c|c|}
\hline \multirow{3}{*}{ Estádio da planta no momento da aplicação } & \multicolumn{5}{|c|}{ Dose do herbicida 2,4-D ( $\mathrm{g} \mathrm{ha}^{-1}$ e.a. $)$} \\
\hline & 0 & 335 & 670 & 1.005 & Média \\
\hline & \multicolumn{5}{|c|}{$\%$ de redução na fitomassa verde da parte aérea } \\
\hline Pré-semeadura & 0 & 5 & 12 & 13 & $7 \mathrm{~b}$ \\
\hline Três folhas expandidas & 0 & 22 & 23 & 33 & $20 \mathrm{a}$ \\
\hline Seis folhas expandidas & 0 & 23 & 25 & 32 & $20 \mathrm{a}$ \\
\hline Pré-florescimento & 0 & 12 & 17 & 19 & $12 \mathrm{a}$ \\
\hline \multirow[t]{2}{*}{ Média } & 0 & 14 & 19 & 24 & 15 \\
\hline & \multicolumn{5}{|c|}{ \% de redução na fitomassa seca da parte aérea } \\
\hline Pré-semeadura & 0 & 2 & 10 & 20 & $8 \mathrm{~b}$ \\
\hline Três folhas expandidas & 0 & 12 & 17 & 31 & $15 \mathrm{a}$ \\
\hline Seis folhas expandidas & 0 & 22 & 26 & 34 & $20 \mathrm{a}$ \\
\hline Pré-florescimento & 0 & 15 & 16 & 19 & $12 \mathrm{a}$ \\
\hline Média & 0 & 13 & 17 & 26 & 14 \\
\hline
\end{tabular}

Médias seguidas pelas mesmas letras na coluna não diferem estatisticamente entre si a 5\% de probabilidade pelo teste de Scott-Knott. 
quando o 2,4-D foi aplicado em pré-florescimento (Tabela 3). Pacheco et al. (2007), trabalhando com a cultura do milheto, também observaram efeito na redução de fitomassa seca com o aumento de doses de 2,4-D. Dessa forma, fica evidente que aplicações tardias de 2,4-D na cultura do sorgo podem comprometer a formação de palhada visando ao sistema plantio direto ou a produção de forragem para fins de alimentação animal.

O aumento das doses de 2,4-D provocou redução linear na produção de fitomassa verde e fitomassa seca das plantas de sorgo (Figura 4). Houve redução de 29 e $18 \%$ na produção de fitomassa verde e de fitomassa seca, respectivamente, com a aplicação de $1.005 \mathrm{~g} \mathrm{ha}^{-1}$. Em condições em que altas doses (ex: $1.608 \mathrm{~g} \mathrm{ha}^{-1}$ ) podem ser exigidas visando ao controle de plantas daninhas, a redução de fitomassa seca pode chegar a $30 \%$, o que representa redução de $0,019 \%$ para cada grama de 2,4-D aplicado, como verificado neste trabalho. A redução na produção de fitomassa seca no ponto de rolagem pode estar associada a uma provável maior taxa de abortamento de flores ocasionado pela aplicação do herbicida em préflorescimento, resultando em menor número de grãos, uma vez que no ponto de rolagem boa parte da fitomassa seca é oriunda de estruturas reprodutivas. Esses resultados demonstram que aplicações de altas doses de 2,4-D na cultura do sorgo devem ser evitadas, principalmente se a finalidade da cultura for a formação de palhada no sistema plantio direto, o aporte de carbono ao solo e a produção de forragem.

A produtividade de grãos foi influenciada tanto pela época de aplicação quanto pelas doses de 2,4-D. A aplicação desse herbicida em pré-florescimento foi a que proporcionou a menor produtividade de grãos (Tabela 4). Corroborando esse resultado, Tamado \& Milberg (2004) também verificaram redução no rendimento de grãos do sorgo em função da aplicação tardia de 2,4-D. A produtividade de

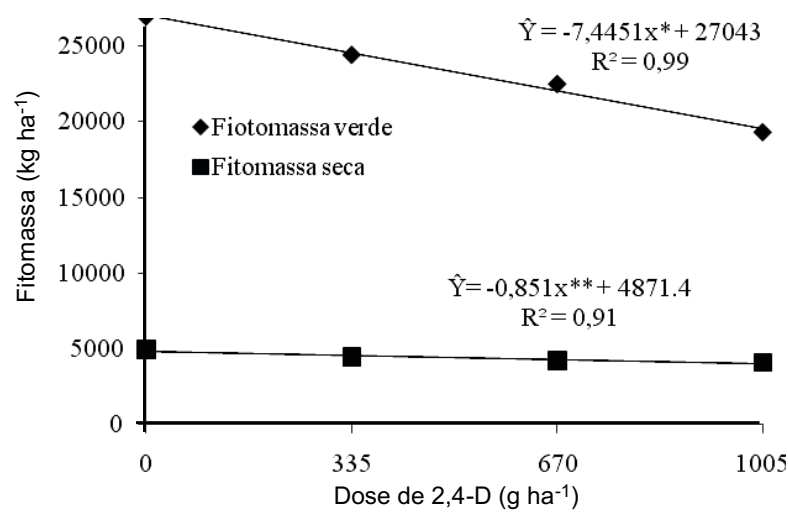

Figura 4 - Valores médios de fitomassa verde e seca de plantas de sorgo avaliada no ponto de rolagem, após a aplicação do herbicida 2,4-D. Nova Xavantina-MT, 2008

Tabela 3 - Fitomassa verde e seca de plantas de sorgo no ponto de rolagem após a aplicação do herbicida 2,4-D, em quatro diferentes épocas. Nova Xavantina-MT, 2008

\begin{tabular}{|c|c|c|c|c|c|}
\hline \multirow{3}{*}{ Estádio da planta no momento da aplicação } & \multicolumn{5}{|c|}{ Dose do herbicida 2,4-D ( $\mathrm{g} \mathrm{ha}^{-1}$ e.a.) } \\
\hline & 0 & 335 & 670 & 1.005 & Média \\
\hline & \multicolumn{5}{|c|}{ Fitomassa verde da parte aérea $\left(\mathrm{kg} \mathrm{ha}^{-1}\right)$ no ponto de rolagem } \\
\hline Pré-semeadura & 23.856 & 25.410 & 21.423 & 18.352 & $22.260^{\mathrm{n}}$ \\
\hline Três folhas expandidas & 25.252 & 22.795 & 21.559 & 19.922 & 22.382 \\
\hline Seis folhas expandidas & 31.651 & 23.524 & 22.656 & 21.156 & 24.747 \\
\hline Pré-florescimento & 27.123 & 26.007 & 24.376 & 17.770 & 23.281 \\
\hline \multirow[t]{2}{*}{ Média } & 26.970 & 24.434 & 22.503 & 19.300 & 23.301 \\
\hline & \multicolumn{5}{|c|}{ Fitomassa seca da parte aérea $\left(\mathrm{kg} \mathrm{ha}^{-1}\right)$ no ponto de rolagem } \\
\hline Pré-semeadura & 4.462 & 4.293 & 4.273 & 4.347 & $4.343 \mathrm{a}$ \\
\hline Três folhas expandidas & 4.820 & 4.602 & 4.309 & 4.135 & $4.467 \mathrm{a}$ \\
\hline Seis folhas expandidas & 5.922 & 4.513 & 4.191 & 4.174 & $4.700 \mathrm{a}$ \\
\hline Pré-florescimento & 4.685 & 4.488 & 4.125 & 3.766 & $4.266 \mathrm{~b}$ \\
\hline Média & 4.972 & 4.474 & 4.224 & 4.105 & 4.443 \\
\hline
\end{tabular}

Médias seguidas pelas mesmas letras na coluna não diferem estatisticamente entre si a $5 \%$ de probabilidade pelo teste de Scott-Knott. ${ }^{\mathrm{ns}}$ não significativo a $5 \%$ pelo teste $\mathrm{F}$. 
Tabela 4 - Produtividade de grãos de sorgo após a aplicação do herbicida 2,4-D, em quatro diferentes épocas. Nova Xavantina-MT, 2008

\begin{tabular}{|l|c|c|c|c|c|c|}
\hline \multirow{2}{*}{ Estádio da planta no momento da aplicação } & \multicolumn{5}{|c|}{ Dose do herbicida 2,4-D (g ha ${ }^{-1}$ e.a.) } \\
\cline { 2 - 6 } & 0 & 335 & 670 & \multicolumn{2}{|c|}{1.005} & Média \\
\cline { 2 - 7 } & \multicolumn{5}{|c|}{ Produtividade de grãos $\left(\mathrm{kg} \mathrm{ha}^{-1}\right)$} \\
\hline Pré-semeadura & 3.604 & 3.423 & 3.374 & 3.006 & $3.351 \mathrm{a}$ \\
\hline Três folhas expandidas & 4.277 & 3.833 & 3.819 & 3.233 & $3.790 \mathrm{a}$ \\
\hline Seis folhas expandidas & 3.840 & 3.659 & 3.534 & 3.152 & $3.546 \mathrm{a}$ \\
\hline Pré-florescimento & 3.368 & 3.541 & 3.041 & 2.680 & $3.158 \mathrm{~b}$ \\
\hline Média & 3.772 & 3.614 & 3.442 & 3.017 & 3.461 \\
\hline
\end{tabular}

Médias seguidas pelas mesmas letras na coluna não diferem estatisticamente entre si a $5 \%$ de probabilidade pelo teste de Scott-Knott.

grãos do sorgo diminuiu à medida que se aumentaram as doses de 2,4-D, com perdas de $0,75 \mathrm{~kg}$ de grãos para cada g de 2,4-D aplicado (Figura 5). Rosales-Robles et al. (2005) também observaram correlação entre efeito fitotóxico à cultura e redução na produtividade do sorgo. Por se tratar de um herbicida hormonal, o 2,4-D ocasiona desequilíbrio hormonal nas regiões meristemáticas, impedindo a formação da panícula, aumentando o abortamento de flores e prejudicando o enchimento de grãos, uma vez que a translocação de fotoassimilado via floema fica prejudicada. Segundo Taiz \& Zeiger (2006), herbicidas auxínicos reduzem o transporte de fotoassimilados no floema.

Os resultados demonstram que a aplicação do 2,4-D prejudica a produtividade do sorgo, sobretudo em doses acima de $1.005 \mathrm{~g} \mathrm{ha}^{-1}$ e.a. em aplicações tardias. De maneira geral, a utilização do 2,4-D em pré-semeadura mostrou

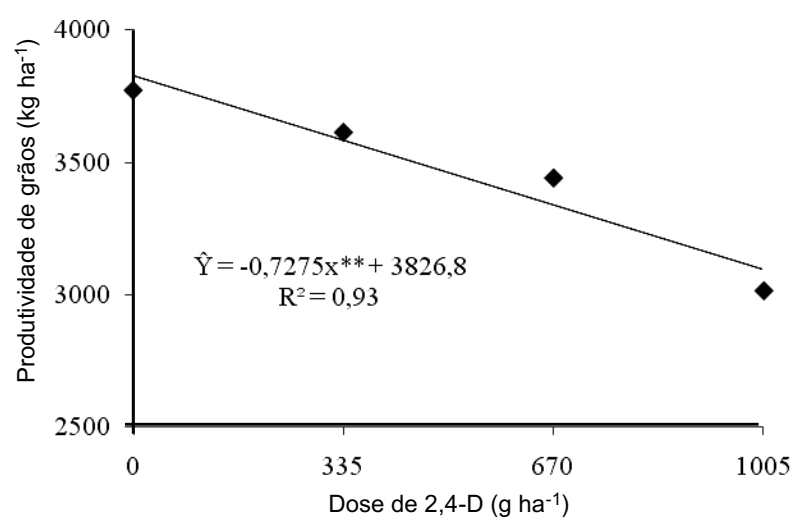

Figura 5 - Valores médios de produtividade de grãos de sorgo após a aplicação do herbicida 2,4-D. Nova Xavantina-MT, 2008 . ser uma boa alternativa no manejo das plantas daninhas, principalmente se a cultura tem como finalidade a produção de forragem.

\section{LITERATURA CITADA}

ABIT, J. M. et al. Differential response of grain sorghum hybrids to foliar-applied mesotrione. Weed Technol., v. 23, n. 1, p. 28-33, 2009

ALMEIDA FILHO, J. E. et al. Desempenho agronômico e estabilidade fenotípica de híbridos de sorgo granífero. R. Bras. Milho Sorgo, v. 9, n. 1, p. 51-64, 2010.

D'ANTONINO, L. et al. Efeito de culturas na persistência de herbicidas auxínicos no solo. Planta Daninha, v. 27, n. 2, p. 371-378, 2009.

DAN, H. A. et al. Tolerância do sorgo granífero ao 2,4-D aplicado em pós-emergência. Planta Daninha, v. 28, n. 4, p. $785-792,2010$.

EMPRESA BRASILEIRA DE PESQUISA AGROPECUÁRIA - EMBRAPA. Centro Nacional de Pesquisa de Solos. Sistema brasileiro de classificação de solos. Rio de Janeiro: 1999. 412 p.

FARINELLI, R.; PENARIOL, F. G.; LEMOS, L. B. Eficiência do herbicida 2,4-D no controle de Raphanus raphanistrum $\mathrm{L}$. em pós-emergência na cultura do milheto. R. Bras. Milho Sorgo, v. 4, n. 2, p. 104-111, 2005.

FONSECA, I. M. et al. Crescimento e nutrição do sorgo (cv. BRS 304) em solução nutritiva. R. Biol. Ci. Terra, v. 8, n. 2 , p. 113-124, 2008.

GERALDO, J. et al. Diferenças em crescimento e produção de grãos entre quatro cultivares de milheto pérola. Pesq.

Agropec. Bras., v. 35, n. 7, p. 1367-1376, 2000. 
MAGALHÃES, P. C.; DURÃES, F. O. M.; SCHAFFERT, R E. Fisiologia da planta de sorgo. Sete Lagoas: Embrapa Milho e Sorgo, 2000. 46 p. (Embrapa Milho e Sorgo Circular Técnica, 3)

PACHECO, L. P. et al. Tolerância do milheto (Pennisetum americanum) ao 2,4-D. Planta Daninha, v. 25, n. 1, p. 173-179, 2007.

PENCKOWSKI, L. H.; PODOLAN, M. J.; LOPEZOVEJERO, R. F. Influência das condições climáticas no momento da aplicação de herbicidas pós-emergentes sobre a eficácia de controle de nabiça (Raphanus raphanistrum) na cultura de trigo. Planta Daninha, v. 21, n. 3, p. 435-442, 2003

RODRIGUES, B. N.; ALMEIDA, F. S. Guia de herbicidas. 5.ed. Londrina: IAPAR, 2005. 591 p.

ROSALES-ROBLES, E. et al. Broadleaf weed management in grain sorghum with reduced rates of postemergence herbicides. Weed Technol., v. 19, n. 1, p. 385-390, 2005.

SHAW, D. R.; ARNOLD, J. C. Weed control from herbicide combinations with glyphosate. Weed Technol., v. 16, n. 1, p. 1-6, 2002.
SILVA, A. A. et al. Herbicidas: classificação e mecanismo de ação. In: SILVA, A. A.; SILVA, J. F. (Eds.). Tópicos em manejo de plantas daninhas. Viçosa, $M G$ : Universidade Federal de Viçosa, 2007. p. 83-148.

STONE, L. F.; PEREIRA, A. L. Sucessão arroz-feijão irrigados por aspersão: efeitos do espaçamento entre linhas, adubação e cultivar no crescimento, desenvolvimento radicular e consumo de água do arroz. Pesq. Agropec. Bras., v. 29, n. 10 , p. $1557-1592,1994$.

TAIZ, L.; ZEIGER, E. Plant physiology. 3.ed. Sunderland: Sinauer Associates, 2006. p. 705.

TAMADO, T.; MILBERG, P. Control of parthenium (Parthenium hysterophorus) in grain sorghum (Sorghum bicolor) in the smallholder farming system in eastern Ethiopia. Weed Technol., v. 18, n. 3, p. 100-105, 2004.

TAMADO, T.; SCHUTZ, W.; MILBERG, P. Germination ecology of the weed Parthenium hysterophorus in eastern Ethiopia. Ann. Appl. Biol., v. 140, n. 3, p. 263-270, 2002.

VIDAL, R. Ação dos herbicidas. Porto Alegre: 2002. 89 p. 